\title{
Serological reactivity to a synthetic analog of phenolic glycolipid I and early detection of leprosy in an area of low endemicity
}

\author{
ELBA GONZÁlEZ-ABREU, ${ }^{*}$ J. A. PON, ${ }^{\dagger} P$. \\ HERNÁDEZ. ${ }^{\ddagger}$ J. RODRIGUEZ, ${ }^{*}$ EUMELIA \\ MENDOZA ${ }^{\dagger}$ MARIA HERNÁNDEZ $^{\dagger}{ }^{\dagger}$ E. CUEVAS, ${ }^{\dagger}$ \\ \& A. B. GONZÁLEZ* \\ *Instituto "Pedro Kouri". Apartado 601, Zona Postal 13, La \\ Habana, Cuba; \\ ${ }^{\dagger}$ Dirección Municipal de Salud, Trinidad, Sancti Spritus, Cuba; \\ ${ }^{\ddagger}$ Centro Provincial de Higiene v Epidemiologia. Sancti Spriritus, \\ Cuba.
}

\begin{abstract}
Accepted for publication 18 August 1995
Summary A total of 23,863 individuals living in an area of low endemicity for leprosy were tested by enzyme-linked immunosorbent assay with a semisynthetic analogue of the phenolic glycolipid I antigen of Mycobacterium leprae. The proportion found positive was $3 \cdot 86 \%$ which was significantly higher than that in a sample of a population known to be free of leprosy. Clinical examinations as well as Mitsuda and skin smear tests were organized for those defined as seropositive. The proportion of individuals with lepromin reactions of less than $3 \mathrm{~mm}$ increased $18.9 \%$ per serological interval as antibodies rose though it was not statistically significant. As a result of the clinical and bacteriological examinations, 2 cases with clinical signs and heavy bacillary load were found, whereas acid-fast bacilli were demonstrated in 2 other individuals without clinical manifestations of leprosy. The usefulness of the system for control purposes is discussed.
\end{abstract}

\section{Introduction}

The development of immunological tests capable of identifying Mycobacterium lepraeinfected individuals has been one of the principal goals of leprosy research since the beginning of this century. ${ }^{1,2}$ Therefore, the isolation and chemical characterization of a $M$. leprae species specific antigen, the phenolic glycolipid I (PGI) ${ }^{3}$ followed by the preparation of artificial antigens containing the species specific moiety of $\mathrm{PGI}^{4}$ made possible their use in serological tests and gave rise to hope for the availability of a long sought serodiagnostic method for the early detection of clinical disease and for the identification of individuals with subclinical infection and, hence, at risk of contracting leprosy. 
After these antigens became available, numerous studies, mainly by an enzyme-linked immunosorbent assay (ELISA), have been conducted throughout the world in order to study the humoral response to $M$. leprae and to evaluate the usefulness of this tool for seroepidemiological surveys and control purpose. Most of the published studies have been cross-sectional, variously comparing antibody levels in panels of sera from patients of all leprosy types as well as from patients' contacts and healthy individuals from leprosy endemic and nonendemic areas. In a recent revision of the subject, Smith $^{5}$ noted that the results from the cross-sectional studies suggest that PGI antibodies provide a sensitive test for multibacillary (MB) leprosy but that it is much less useful for the detection of paucibacillary (PB) cases and pointed out, on the basis of this latter observation and of a reasonable statistical assumption, that it appears that the contribution that serodiagnostic methods can make over normal diagnostic procedures is rather limited at the present time; and that, to assess more rigorously the usefulness of PGI antibody levels in predicting who will develop clinical disease, it is necessary to conduct studies in which individuals are followed prospectively for signs of leprosy after sera have been collected from apparently healthy individuals.

In Cuba, previous studies ${ }^{6,7}$ showed some evidence that a positive result of the serological test could lead to the detection of individuals without clinical signs but with acid-fast bacilli (AFB) demonstrable in their skin smears, as well as of cases with early clinical signs and others with more advanced disease who were shedding AFB and had not been detected through the normal activities of the control programme. These findings offered encouragement to undertake a wider seroepidemiological study since skin-smear positive cases are thought to make the greatest contribution to the spread of M. leprae infection.

\section{Materials and Methods}

\section{STUDY AREA}

The study area was the city of Trinidad and 3 other small neighbouring villages called Casilda, Condado and Caracusey. Trinidad, head of the municipality of the same name, is situated in the central part of Cuba near the southern shore. On 31 December 1992, 69 leprosy patients were registered in the municipality, all but one were living in the study area and were receiving or had completed multidrug therapy (MDT). In the area, as in the whole country, leprosy rates are low. In the 13-year period 1980-92, 42 patients were diagnosed $(X=3 \cdot 2)$. According to the Madrid classification, 12 of them were classified as tuberculoid, 10 as indeterminate, 2 as dimorphous and 18 as lepromatous. The local laboratory found $13(31 \%)$ of these cases as skin-smear positive when detected. The total population of the study area was estimated to be 44,578 inhabitants (Table 1) at the beginning of the work (October 1992).

\section{BLOOD COLLECTION}

Since there is no leprosy in children in the study area, the eligible population considered was above the age of 9 years, and was estimated at 37,895 (Table 1). Blood was obtained by a finger-prick and absorbed onto a small piece of Whatman No. 4 Chr paper attached to a form for individual identification data. The papers were air-dried at ambient 
temperature in the shadow, kept in sealed plastic bags under refrigeration for not more than 15 days in the field and sent to the Tropical Medicine Institute "Pedro Kouri" (JPK), Havana, where they were stored at $-20^{\circ} \mathrm{C}$ usually for not more than 1 month before testing. Known leprosy patients were excluded from the study. Approximately half of the samples were collected in October 1992 and the rest in January 1993.

Burgess et al. $^{8}$ stated that test specificity estimates have been based on sera from nonleprosy cases living in endemic areas or on sera for nonendemic areas. Neither of these is ideal in so far as control individuals from endemic areas might be infected with $M$. leprae and individuals from nonendemic areas are liable to lack exposure to other potentially cross-reacting infections, which will in fact determine specificity when the tests are applied in endemic areas. Trying to minimize this inconvenient fact, blood spots were collected from 430 individuals, aged above 9 years, living in a small village called Puerto Manati. This village is situated in the province of Las Tunas which is the Cuban province with the lowest leprosy rates, its mean annual detection rate is only 0.9 per 100,000 in the decade 1980-89 and, particularly, neither present nor former leprosy cases are registered in Puerto Maniti where the population is known to be very stable.

ELISA

The procedure was basically the same as that described by Cho et al. ${ }^{9}$ with some modifications. The antigen used was ND-A-BSA prepared at the Havana University Faculty of Chemistry and obtained by courtesy of Dr V. Verez. This antigen had been previously tested in parallel with Gigg DISSACH, provided by WHO, with excellent results. Discs of 5-mm diameter, found to absorb about $5 \mu \mathrm{l}$ blood, were punched from the blood-impregnated paper and eluted overnight at $4^{\circ} \mathrm{C}$ in $400 \mu \mathrm{l}$ of phosphatebuffered saline (PBS) containing $2 \%$ skimmed milk to an equivalent serum dilution of $1 / 200$. The antigen was dissolved in a carbonate-bicarbonate coating buffer ( $\mathrm{pH} 9 \cdot 6$ ) to the concentration of $2 \mu \mathrm{l} / \mathrm{ml}$, and added at the amount of $50 \mu \mathrm{l}$ to wells of flexible PVC plates (Flow Laboratories) which were incubated at $37^{\circ} \mathrm{C}$ for $18 \mathrm{hr}$. Wells were washed 4 times with PBS, blocked by the addition of $100 \mu$ l of PBS containing 5\% skimmed mild and incubated at $37^{\circ} \mathrm{C}$ for $1 \mathrm{hr}$ in a moist chamber. The contents were aspirated and $50 \mu \mathrm{l}$ of the eluted samples were added. Plates were incubated at $47^{\circ} \mathrm{C}$ for $1 \mathrm{hr}$, washed 6 times with PBS, followed by the addition of rabbit anti-human JgM-peroxidase conjugate reagent (DAKO-Immunoglobulins a/s, Denmark) diluted 1/1000 in PBS-2\% skim milk. After a $1 \mathrm{hr}$ incubation and 4 further washings, $50 \mu \mathrm{l}$ of $\mathrm{H}_{2} \mathrm{O}_{2}$-O-phenylene diamine substrate-dye reagent in citrate phosphate buffer were added and incubated at $37^{\circ} \mathrm{C}$ for 10 min. Reactions were terminated with $2 \cdot 5 \mathrm{~N} \mathrm{H}_{2} \mathrm{SO}_{4}$ and the absorbance was read at $492 \mathrm{~nm}$ in a Titertak Multiskan MC reader. Pool of sera from untreated lepromatous patients adjusted to give an OD value of 1.000 and from healthy subjects were included as controls in each plate. In order to save time and materials, the samples were tested in two steps: first, each elution was added to only 1 antigen coated well and, second, those giving OD readings higher than 0.200 were tested again, this time using 2 antigen coated wells and 1 BSA coated well. The results were expressed as the mean OD of antigen duplicates minus the OD of the BSA well. A correction factor was applied to compensate for plate-to-plate variation in results recorded for the positive control pool. On the basis 
of the results observed on the Puerto Manati samples, the criterion for positivity was an OD reading above $0 \cdot 199$.

CLINICAL AND BACTERIOLOGICAL EXAMINATION AND MITSUDA TEST

Clinical and bacteriological examination as well as Mitsuda tests were organized for those with a serological test result above the established cut-off value. The skin-smear test would be performed in individuals showing OD readings above 0.399 or when skin lesions could possibly be leprosy were found irrespective of the serological results. Clinical and bacteriological examinations were performed in May 1993 by 2 doctors trained in leprosy. The tissue pulp samples for the smears were taken from both earlobes, left elbow, left knee and skin lesions if found. The lepromin used was prepared at the IPK laboratory from $M$. leprae infected armadillo tissues kindly provided by WHO and adjusted to contain $4 \times 10^{7}$ AFB per millilitre.

\section{Results}

The number of individuals from the study area who were serologically tested was 23,863 that is $63.0 \%$ of the eligible population. Table 2 shows the frequency distribution of ELISA results from both the study population and the presumably $M$. leprae noninfected controls from Puerto Manati. None of the control samples showed an OD reading higher than $0 \cdot 299$ and only 2 in the interval $0 \cdot 200-0 \cdot 299$. If the criterion for positivity is set at an OD value higher than $0 \cdot 199$, then the resulting test specificity is $99 \cdot 5 \%$. Thus, the overall positivity rate was $3 \cdot 86 \%$ in the study population, significantly higher than in the Puerto Manati population (comparison of 2 proportions, $Z=15 \cdot 32$, $P<0 \cdot 0001)$.

Not all the subjects found to be ELISA positive could be clinically examined and Mitsuda tested (Table 3). Table 4 shows the results of the lepromin tests according to the serological intervals. Although there is a linear relationship between the 2 variables $\left(\chi^{2}=10 \cdot 11186 \mathrm{df}\right)$ with a slope $(\beta)=0 \cdot 1891$ (Model $\left.P=\alpha+\beta x i\right)$ which means that the proportion of individuals with lepromin reactions of less than $3 \mathrm{~mm}$ increases $18.91 \%$ per interval of PGI antibodies as these latter rise, this increase is not statistically significant $\left(\chi^{2}=1.3491 \mathrm{df}\right)$ possibly due to the small number of individuals in the highest OD intervals.

Table 1. Estimated population of the study area

\begin{tabular}{lrr}
\hline Area & Total & $>9$ years \\
\hline Trinidad & 34,190 & 29,062 \\
Casilda & 4424 & 3763 \\
Condado & 2916 & 2479 \\
Caracusey & 3048 & 2591 \\
Total & 44,578 & 37,895 \\
\hline
\end{tabular}


Table 2. Number (\%) of test results according to serological intervals

\begin{tabular}{lrc}
\hline Serological interval & \multicolumn{1}{c}{ Study area } & Puerto Manati \\
\hline $0 \cdot 200$ & $22,958(96 \cdot 207)$ & $428(99 \cdot 535)$ \\
$0 \cdot 200-0 \cdot 299$ & $542(2 \cdot 271)$ & $2(0.465)$ \\
$0 \cdot 300-0 \cdot 399$ & $217(0 \cdot 909)$ & 0 \\
$0 \cdot 400-0 \cdot 499$ & $94(0 \cdot 394)$ & 0 \\
$0 \cdot 500-0 \cdot 599$ & $36(0 \cdot 151)$ & 0 \\
$0 \cdot 600-0 \cdot 699$ & $10(0.042)$ & 0 \\
$0 \cdot 700-0 \cdot 799$ & $3(0.012)$ & 0 \\
$0 \cdot 800-0 \cdot 899$ & $2(0.008)$ & 0 \\
$0 \cdot 900-0.999$ & $1(0.004)$ & 0 \\
& & \\
\hline
\end{tabular}

As for the clinical examinations, 2 old men, 60 and 71 years old, presented with signs of leprosy. The first case showed with moderate infiltration of both earlobes, partial loss of the eyebrows laterally and scarce micronodules in the left upper limb, this man was a household contact (husband) of a registered and treated lepromatous patient and had refused previous examinations organized by the programme for patients' contacts. The second case also presented with some micronodules in the left upper limb and both lower limbs, no other clinical sign was noted in this case, who was a neighbour of the former case. Both were found to be skin-smear positive with a heavy bacillary load. A third case, a 43-year-old woman was found to be skin-smear positive with a Bacteriological Index (BI) of $2+$ at all sampled skin sites but, remarkably, no clinical signs at all were noted when examined. This case was a nonhousehold contact (niece) of a registered and treated lepromatous patient. All 3 cases (Table 5) were promptly put on MDT as recommended by WHO for MB patients. ${ }^{10}$ Yet, in the skin smears from a fourth case 1 AFB could be seen, the smears were then carefully scrutinized for more AFB but no further organisms were observed. The OD value for this case was 0.659 , his clinical examination was negative, his lepromin reaction was $9 \mathrm{~mm}$ and no contact with leprosy was known. This case was administered the MDT regimen recommended by WHO for PB leprosy. ${ }^{10}$ Apart from the cases already described, leprosy was diagnosed in a self-reporting

Table 3. Clinical examinations and Mitsuda tests performed on seropositive individuals

\begin{tabular}{lcrr}
\hline $\begin{array}{l}\text { Serological } \\
\text { interval }\end{array}$ & $\begin{array}{c}\text { Number in } \\
\text { interval }\end{array}$ & $\begin{array}{c}\text { Mitsuda } \\
\text { No. }(\%)\end{array}$ & $\begin{array}{c}\text { Clinical } \\
\text { No. }(\%)\end{array}$ \\
\hline $0 \cdot 200-0 \cdot 299$ & 542 & $182(33 \cdot 6)$ & $122(22 \cdot 5)$ \\
$0 \cdot 300-0 \cdot 399$ & 217 & $174(80 \cdot 1)$ & $152(70 \cdot 0)$ \\
$0 \cdot 400-0 \cdot 499$ & 94 & $76(80 \cdot 8)$ & $74(78 \cdot 7)$ \\
$0 \cdot 500-0 \cdot 599$ & 36 & $29(80 \cdot 5)$ & $23(63 \cdot 8)$ \\
$0 \cdot 600-0 \cdot 699$ & 10 & $8(80 \cdot 0)$ & $8(80 \cdot 0)$ \\
$0 \cdot 700-0 \cdot 799$ & 3 & $2(66 \cdot 6)$ & $2(66 \cdot 6)$ \\
$0 \cdot 800-0 \cdot 899$ & 2 & $2(100)$ & $2(100)$ \\
$0 \cdot 900-0 \cdot 999$ & 1 & $1(100)$ & $1(100)$ \\
Total & 905 & $474(52 \cdot 3)$ & $384(42 \cdot 4)$ \\
\hline
\end{tabular}


Table 4. Results of the Mitsuda tests according to serological intervals

\begin{tabular}{lrrr}
\hline & \multicolumn{3}{c}{ Mitsuda test } \\
$\begin{array}{l}\text { Serological } \\
\text { interval }\end{array}$ & $0-2 \mathrm{~mm} \mathrm{( \% )}$ & $>2 \mathrm{~mm}(\%)$ & Total \\
\hline $0 \cdot 200-0 \cdot 299$ & $37(20 \cdot 3)$ & $145(79 \cdot 7)$ & 182 \\
$0 \cdot 300-0 \cdot 399$ & $24(13 \cdot 7)$ & $150(86 \cdot 3)$ & 174 \\
$0 \cdot 400-0 \cdot 499$ & $15(19 \cdot 7)$ & $61(80 \cdot 3)$ & 76 \\
$0 \cdot 500-0 \cdot 599$ & $7(24 \cdot 1)$ & $22(78 \cdot 2)$ & 29 \\
$0 \cdot 600-0 \cdot 699$ & $1(12 \cdot 5)$ & $7(75 \cdot 5)$ & 8 \\
$0 \cdot 700-0 \cdot 799$ & $1(50 \cdot 0)$ & $1(50 \cdot 0)$ & 2 \\
$0 \cdot 800-0 \cdot 899$ & $1(50 \cdot 0)$ & $1(50 \cdot 0)$ & 1 \\
$0 \cdot 900-0 \cdot 999$ & $1(100)$ & 0 & 2 \\
Total & $87(18 \cdot 3)$ & $387(81 \cdot 7)$ & 474 \\
& & & \\
\hline
\end{tabular}

individual who was classified as tuberculoid and had been negative in the serological test and, hence, not included in the study. No other leprosy cases were detected in the study area in the year 1993.

\section{Discussion}

In spite of the very low morbidity rates for leprosy in the study area, the PGI seroreactivity characterized its population as different from that presumably free of the disease in Puerto Manati. The frequency distribution of OD values observed in this study and that reported for leprosy contacts by other workers ${ }^{11-14}$ suggests that, on exposure to $M$. leprae, most individuals do not display a humoral response or do it at a low level, whereas the small proportion who do it at a high level diminishes as the PGI antibodies increase. This observation seems to correspond well with the fact that leprosy is a disease of low incidence. It also points to the risk of contracting MB disease for those with increased seroreactivity because the antibody response to PGI correlates directly to the increasing antigen load from the tuberculoid pole to the lepromatous pole of the leprosy spectrum. ${ }^{1}$

Little information is available on the relationship between PGI antibodies and the lepromin reaction in healthy people. This is interesting as it is believed that $10 \%$ of lepromin negative people living in close contact with lepromatous leprosy patients

Table 5. Cases detected in the present study

\begin{tabular}{|c|c|c|c|c|c|}
\hline Case & $\begin{array}{c}\text { ELISA } \\
\text { (O.D) }\end{array}$ & $\begin{array}{c}\text { Mitsuda } \\
\text { test }\end{array}$ & $\mathrm{BI}$ & $\begin{array}{l}\text { Clinical } \\
\text { signs }\end{array}$ & $\begin{array}{l}\text { Contact } \\
\text { condition }\end{array}$ \\
\hline 1 & $0 \cdot 244$ & $0 \mathrm{~mm}$ & $5+$ & Minimal & Household \\
\hline 2 & 0.593 & $0 \mathrm{~mm}$ & $6+$ & Minimal & Non-household \\
\hline 3 & $0 \cdot 448$ & $0 \mathrm{~mm}$ & $2+$ & None & Non-household \\
\hline 4 & 0.659 & $9 \mathrm{~mm}$ & $1+$ & None & Unknown \\
\hline
\end{tabular}


eventually develop leprosy, mainly of the lepromatous type, and that considerably fewer lepromin positives with the same contact condition develop the disease, and then only tuberculoid leprosy. ${ }^{2}$ Therefore, a parallel assessment of cell-mediated immunity by the Mitsuda test should help the prognostic evaluation of detectable PGI antibodies in healthy individuals. In New Caledonia, Desforges et al. ${ }^{14}$ followed 17 contacts for PGI antibodies during 3 years and tested them for the Mitsuda reaction at the second sample. Of these, 11 had a positive lepromin test, 5 of them were seronegative at the first sample and 6 others were seropositive. None of these subjects developed overt leprosy during the study period. Of the 6 lepromin negative individuals, 4 were seropositive at the first sample, at the second sample 3 were still positive and 1 of them had developed an indeterminate form of leprosy. Among the 2 subjects who were initially seronegative, 1 remained seronegative and healthy, the second became strongly seropositive and developed BT leprosy. In Guadaloupe, Agis et al. ${ }^{13}$ found none of the 48 bloodbank donors and $4 \%$ of 69 leprosy contacts to be seropositive in both tests. David et al ${ }^{15}$ found that healthy Mitsuda reactors produced PGI antibodies upon exposure to $M$. leprae as often as healthy nonreactors among 534 young army recruits in Brazil, indicating that the probability of subclinical disease was the same in all individuals. In the present study, it was evident that even individuals with high OD values were capable of showing positive lepromin reactions. There is also a tendency though not significant, possibly because the numbers in the highest serological intervals are very small, for an increase in the proportion of lepromin negatives as the OD values rise and this also seems to correspond with the notion that only a small proportion of lepromin negative subjects, when exposed to infection, eventually develop lepromatous leprosy since this disease type is generally associated with high antibody levels.

The main objective of most published research works on PGI and its semisynthetic analogs has been to assess the usefulness of serological methods as a tool for control purposes. The ultimate goal of leprosy control is to interrupt the transmission of the causative agent and, eventually, the eradication of the disease. To achieve this it is necessary to detect and administer MDT as early as possible to as many ' $M$. leprae transmitters' as possible. Therefore, while the very high sensitivity of the test is widely recognized for the highly bacilliferous untreated lepromatous cases, the matter of its usefulness as a control tool should be discussed further. In a previous study conducted by the authors ${ }^{6}$ among 3366 contacts, the test results led to the detection of 3 early cases who were classified as indeterminate, 2 skin-smear positive cases with clinical signs and, yet, another case in whom not a single clinical sign was observed but whose skin smears were positive showing a BI of $3+$. Four of these cases were lepromin negative. In another previous study ${ }^{7}$ conducted among 1200 work-place contacts of 2 lepromatous patients, a positive OD value led to the detection of a contact whose only clinical sign was a moderate infiltration of one earlobe from which a skin smear showed a BI of $1+$. This case was lepromin negative. In the present study, the 2 cases with clinical signs can be considered as early detected. Strikingly, in 1 of them the OD reading (0.244) was only slightly above the cut-off point. Though PGI antibody levels correlated directly with bacillary load, individual variation has been observed. ${ }^{16}$ Again, a positive ELISA result led to the detection of a clinically healthy lepromin negative contact but skin-smear positive. With respect to the healthy lepromin positive individual with only 1 skin smear found to be AFB, the simplest explanation may be that it was a saprophytic organism contaminating the skin. But his OD reading was 0.659 and it is not known if he was 
incubating PB leprosy or if it was a self-healing subclinical infection and, by pure chance, 1 of his few $M$. leprae were seen when using a microscopy.

In the study by Chanteau et al. ${ }^{12}$ among a group of 1123 contacts in Polynesia followed up for periods of up to 6 years, only 1 of 10 individuals who developed leprosy was lepromatous and this case had shown a high PGI antibody level for 20 to 30 months before diagnoses. In The Philippines, Douglas et al. ${ }^{17}$ found that leprosy developed in 3 of 36 contacts with elevated PGI antibody levels but only in 1 of 285 of those without elevated levels in a study of household contacts over a period of 2 years. But all 3 new seropositive patients were found by biopsy to have a BI of $4+$ or higher and had been antibody positive 4, 6 and 18 months respectively before the clinical onset. In the study conducted by Ulrich et al. ${ }^{18}$ among contacts in Venezuela, the test results for each individual serum sample were expressed as a proportion of the OD value of the positive control in each microtitre plate, using as the positive control a pool of sera from 6 patients with LL or BL leprosy with known high levels of antibodies to PGI. If a cut-off point had been set at 0.250 sample/positive control ratio, $14(70 \%)$ of the 20 cases who subsequently developed leprosy had been considered as seropositive and only 6 indeterminate cases had been considered as seronegative. All 7 multibacillary cases (1 LL, $2 \mathrm{BL}$ and $4 \mathrm{BB}$ ) were above that supposed cut-off point. Moreover, a strong association was found between the antibody level and the risk of leprosy. Those with high antibody levels were at over a 10-fold increased risk of leprosy compared to those in the lowest category and there was a gradient in risk with antibody level. ${ }^{5}$

A positive test result cannot display a high predictive value for overt disease since infection is far more common than is evidenced by clinically manifested cases. ${ }^{19}$ Thus, the test should be useful for screening populations or groups of individuals at risk and would allow to detect the small proportion that are seropositive for clinical examination and Mitsuda test. Yet, the results of the Mitsuda test will restrict further the number of individuals to be followed up and so, the health care services would not be oversubscribed. Another problem is the feasibility of carrying out such a strategy as many endemic areas may lack the necessary infrastructure for performing the serological tests, however, solutions may also be found. Blood collection onto filter paper is so easy that community volunteers may be trained to do it. A very high productivity may be achieved by a central laboratory with a good work organization and, once the laboratory is equipped, at a satisfactorily low cost. Leprosy control by health education and administration of MDT to self-reporting cases, might not be as successful with respect to a foreseeable interruption of $M$. leprae transmission in areas of predominantly $\mathrm{MB}$ disease as it may be in areas of predominantly PB disease due to the relatively greater number of cases acting as sources of infection before the disease clinically manifested or not is diagnosed and treated. Therefore, in at least such former areas there may be a role for PGI serology in leprosy control.

\section{Acknowledgment}

The authors wish to thank Dr R. Gil, chief of the national leprosy control programme, and Dr M. Villar, epidemiologist in charge of this programme in the province of Las Tunas, for their help in obtaining blood samples from the Puerto Manati population. 
Our thanks go also to Dr V. Hidalgo and Mr R. Pérez for their help in organizing the work in the study area.

\section{References}

1 Anonymous. Serological tests for leprosy. Lancet, 1986; i: 533-5.

2 Melson R. Editorial: Serodiagnosis of leprosy: the past, the present and some prospects for the future. Int $J$ Lepr. 1983; 51: 235-52.

3 Hunter SW, Brennan PJ. A novel phenolic glycolipid from Mycobacterium leprae possibly involved in immunogenicity and pathogenicity. J Bacteriol, 1981; 147: 728-35.

4 Fujiwara T, Hunter SW, Cho SN, Aspinall GO, Brennan PJ. Chemical synthesis and serology of the disaccharides and trisaccharides of phenolic glycolipid antigens from the leprosy bacillus and preparation of disaccharide protein conjugate for serodiagnosis of leprosy. Infect Immun, 1984; 43: 245-52.

5 Smith PG. Editorial: The serodiagnosis of leprosy. Lepr Rev, 1992; 63: 97-100.

${ }^{6}$ González-Abreu E, Mora N, Pérez M, Perez J, González AB. Serodiagnosis of leprosy in patients' contacts by enzyme-linked immunosorbent assay. Lepr Rev, 1990; 61: 145-50.

7 Gil RE, Baez H, González-Abreu E, Rodriguez J, González AB. Estudio de un foco de lepra en un centro industrial en Cuba. Rev Leprol. Fontilles. 1994; in press.

${ }^{8}$ Burgess PJ, Fine PEM, Ponighaus JM, Draper C. Serological tests in leprosy. The sensitivity, specificity and predictive value of ELISA tests based on phenolic glycolipid antigens, and the implications for their use in epidemiological studies. Epidem Inf, 1988; 101: 159-71.

9 Cho SN, Yanagihara DL, Hunter SW, Gelber RH, Brennan PJ. Serological specificity of phenolic glycolipid I from Mycobacterium leprae and use in serodiagnosis of leprosy. Infect Immun, 1983; 41: 1077-83.

10 WHO Study Group. Chemotherapy of leprosy for control programmes. Technical Report Series, No. 675; WHO: Geneva, 1982.

11 Menzel S, Harboe M, Bergsvik H, Brennan PJ. Antibodies to a synthetic analog of phenolic glycolipid I of Mycobacterium leprae in healthy household contacts of patients with leprosy. Int J Lepr, 1987; 55: 617-25.

12 Chanteau S, Cartel JL, Guidi C, Plichart R, Bach MA. Seroepidemiological study of 724 household contacts of leprosy patients in French Polynesia using disaccharide-octyl-BSA as antigen. Int J Lepr, 1987; 55: 62632.

13 Agis F, Schlich P, Cartel JL, Guidi C, Bach MA. Use of anti-M. leprae phenolic glycolipid I antibody detection for early diagnosis and prognosis of leprosy. Int J Lepr, 1988; 56: 527-36.

14 Desforges S, Bobin P, Brethes B, Huerre M, Moreau JP, Bach MA. Specific anti-M. leprae PGL-I antibodies and Mitsuda reactions in the management of household contacts in New Caledonia. Int J Lepr, 1989; 57: 794-800.

15 David HL, Papa F, Cruaud P, Berlie HC, Maroja M, Salem JI, Costa MF. Relationships between titers of antibodies immunoreacting against glycolipid antigens from Mycobacterium leprae and Mycobacterium tuberculosis, the Mitsuda and Mantoux reactions and bacterial loads: Implications in pathogenesis, epidemiology and serodiagnosis of leprosy and tuberculosis. Int J Lepr, 1992; 60: 208-24.

16 Bach MA, Wallach D, Flageul B, Hoffenbach A, Cottenol F. Antibodies to phenolic glycolipid I and to whole Mycobacterium leprae in leprosy patients: Evolution during therapy. Int J Lepr, 1986; 54: $256-67$.

17 Douglas JT, Celona RV, Abalos RM, Madarang MG, Fa jardo T. Serological reactivity and early detection of leprosy among contacts of lepromatous patients in Cebu, Philippines. Int J Lepr, 1987; 55: 718-21.

18 Ulrich M, Smith PG, Zuñiga M, Sampson C, Centeno M, Garicia V, Manrique X, Salgado A, Convit J. IgM antibodies to native phenolic glycolipid I in contacts of leprosy patients in Venezuela: epidemiological observations and a prospective study of the risk of leprosy. Int J Lepr, 1991; 59: 405-15.

19 WHO Expert Committee on Leprosy. Sixth Report. Technical Report Series No. 768, WHO: Geneva, 1988. 